\title{
ASPECTS ON IMPLEMENTATION OF AN INTEGRATED WASTE MANAGEMENT SYSTEM IN THE RURAL AREA
}

\author{
Andreea BUCUR \\ Technical University of Cluj-Napoca \\ 28 Memorandumului, 400114, Cluj-Napoca, Romania \\ andreea.bucur@gascop.ro
}

\begin{abstract}
The issue of waste management in terms of environmental protection is one of the important problems facing humanity, especially in the large agglomeration areas, and in the rural area, the interests are more limited.

The present paper presents theoretical aspects regarding the implementation of an integrated waste management system in the rural area.
\end{abstract}

Keywords: strategy, renewable resources, medium quality, management

\section{Introduction}

The issue of waste management in the rural area is of increasing interest in recent years, given that throughout the world there are thousands of tons of waste, a rational management is required, while ensuring the protection and conservation of nature, diversity wildlife and its sustainable use, [2], [4].

Landfills by developing and implementing a waste management can find ways and solutions to gain new energy by using mass waste in compost largely. These activities concern the collection, transport, treatment and recovery of waste. All these activities of waste management consider the observance and application of environmental protection norms as well as the compliance with the requirements imposed by the legislative framework.

Waste generation is the indicator that are the best illustrates the extent of the interaction between human activities and the environment. Waste generation usually follows consumption and production trends. For example, the generation of household waste (quantity/inhabitant) increases as the standard of living increases. The increase of the economic production, but also the inefficient management of the resources, lead to the generation of large quantities of waste, [5].

This paper refers to the development of a pilot study on the implementation of a waste management system covering an area Muresan or Ogra comprising a total of five villages: Ogra, Dileu Old Giulus, Lăscud and Vaideiu.

The pilot study is based on the results of a questionnaire applied [3] in the rural area of Mures, namely the commune of Ogra in the Mures county.

Following the processing of the data provided by the citizens of the city on the environmental problems, in order to diagnose and perceive the current state of the environment, several aspects are highlighted regarding the distribution of responsibilities regarding the protection of the environment, being useful also for knowing the activities that the citizens carry out for preserving and improving the quality of life and the environment.

In order to implement an integrated waste management system, the following aspects were highlighted:

- the implementation of such a system is beneficial to the population from the Ogra commune area, while also contributing to the protection of the environment;

- development and implementation of a pilot activity in rural areas, respectively the development of energy potential in the area.

2. Implementation of a waste management system at rural level

(C) 2019 Published by University Press. This is an open access article licensed under the Creative Commons Attribution-NonCommercial-NoDerivs License (http://creativecommons.org/licenses/by-nc-nd/3.0/). 
By constantly taking over an amount of waste from an agro-farm or farm, an integrated management system can be defined regarding the management of these matters, in order to obtain different types of energy, used at the farm, farm or other level of household. Thus we can say that we can ensure a pollution-free and energy-independent rural environment, based only on the intelligent use of energy resources resulting from recycling.

In Fig. 1 we can see a logical scheme in which is presented regarding the opportunities for the recovery of waste from an agro-farm or rural community.

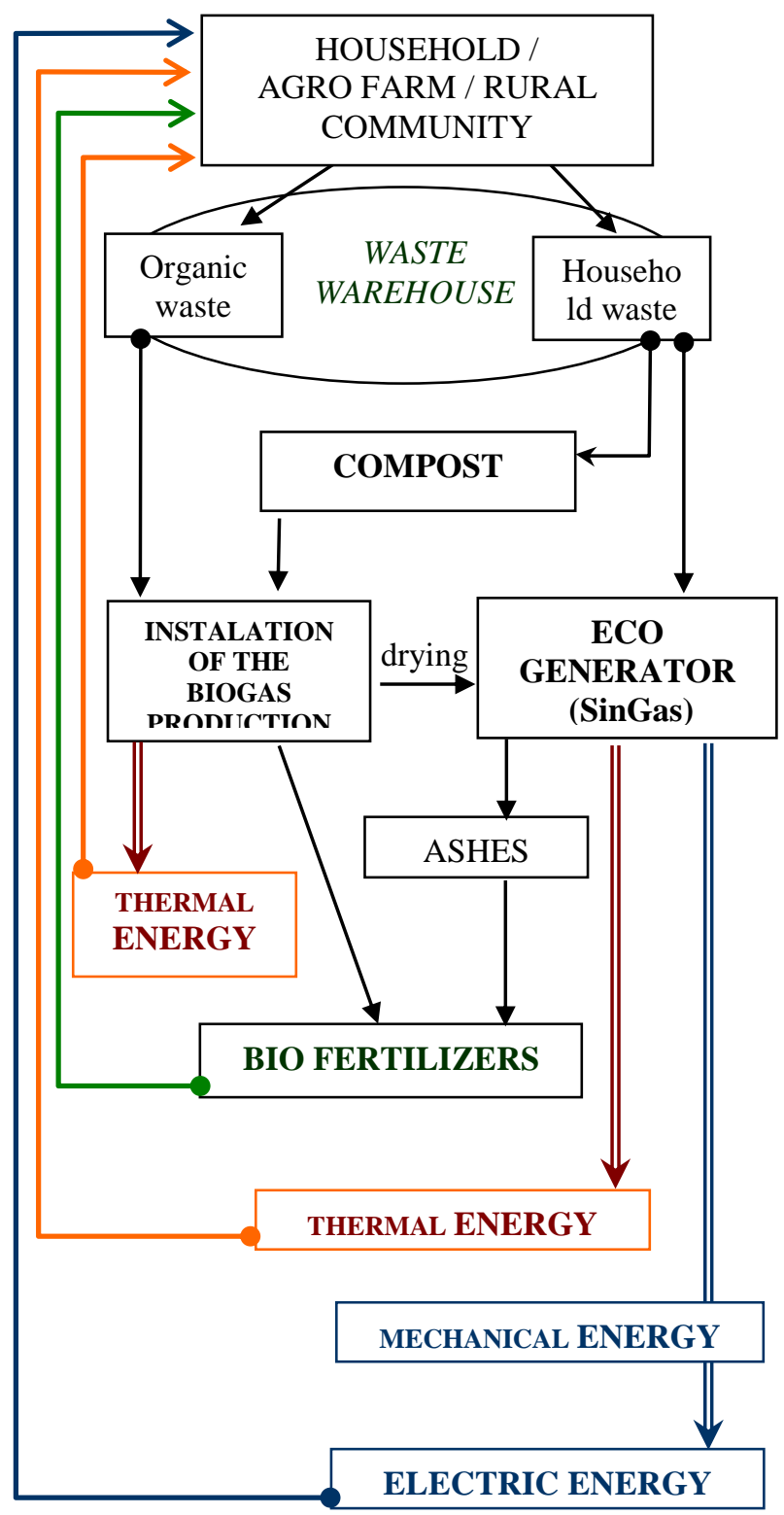

Fig. 1: Valorification of the waste

In according to the principle scheme present in Fig.1, it can be considered that following the selective collection of waste at the rural community level, a number of advantages can be obtained, respectively:

- rom the organic waste based on the controlled fermentation, biogas can be obtained and which can be a gas fuel needed for the thermal installations in order to obtain thermal energy;

- of household waste can be obtained after processing screening / selection / burning, electrical energy;

- from the matter resulting during the thermophysical-chemical processes, bio fertilizer results that can be reintegrated into agriculture.

Based on this theoretical scheme, a closed energy system can be identified that will provide or supplement the community energy resources, [7], [8], [16].

Depending on the location and the distances to other nearby farms, it may be proposed to develop a cluster of biogas plants in the area of interest.

One of the basic ideas, if there are more farmers interested in this system is to develop a biogas production facility in a central location and the other raw material suppliers and / or users of the thermal energy to connect to this system. Developing such a cluster that integrates agricultural farms (raw material producers) biogas plant and plants that use the heat generated will be much more efficient.

The use of the heat generated by the combustion of the resulting biogas is in fact the key to the efficient use of some potential biogas plants. The efficient use of heat is also limited to the development of adjacent industries / activities such as the processing and storage of agricultural products, the production of greenhouses, or the use of the heat generated for heating the houses (with the costs related to the development of the infrastructure needed for housing transport, [9], [10].

\section{- Biogas installation}

There are several types of concepts for agricultural biogas plants around the world, in Fig.2 a diagram of the principle of such a biogas production station can be highlighted.

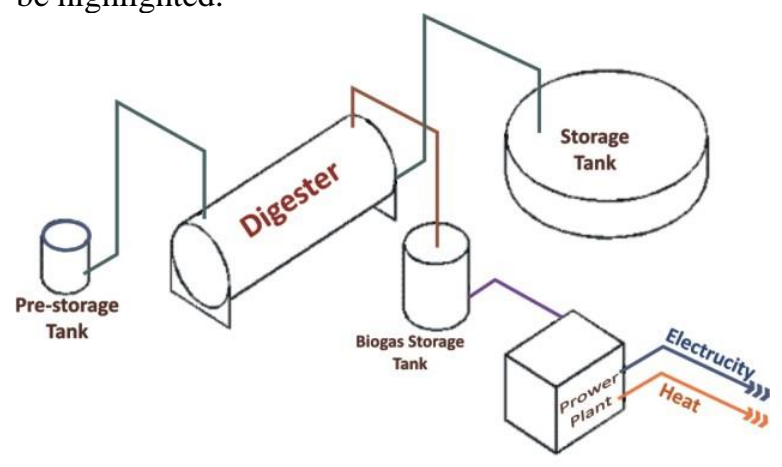

Fig. 2: Biogas energy plant solution

These installations have a common principle: the garbage is collected in a pre-storage tank, near the digester and pumped into the digester, which is a gastight tank, made of steel or concrete, insulated to maintain a constant process temperature

The average retention time (HRT) is usually between 20 and 40 days, depending on the type of 
substrate and the digestion temperature. The digester is used as fertilizer on the farm, and the surplus is sold to farms in the area near the plant.

The biogas produced is used in a gas engine, for the production of electricity and heat 10 to $20 \%$ of the heat and electricity produced is used for the operation of the biogas plant and for the internal needs of the farmer, and the surplus is sold to the electricity companies. and, respectively, to neighboring heat consumers.

The use of the heat generated by the combustion of the resulting biogas is in fact the key to the efficient use of some potential biogas plants.

The efficient use of heat is also limited to the development of adjacent industries / activities such as the processing and storage of agricultural products, the production of greenhouses, or the use of the heat generated for heating the houses (with the costs related to the development of the infrastructure necessary for the transport to homes).

\section{- SinGas Generator}

The system is based on the pyrolysis of the waste material resulting from the garbage, wastes of any kind, by heating and decomposition at high temperatures of $700-800{ }^{\circ} \mathrm{C}$, supplied by heating the electrical resistance located inside the device.

The process does not pollute, through successive filtration results a synthesis gas (sinGas), which it is used like as fuel for an electric generator. Depending on the capacity of the installation, the electric current generator is designed.

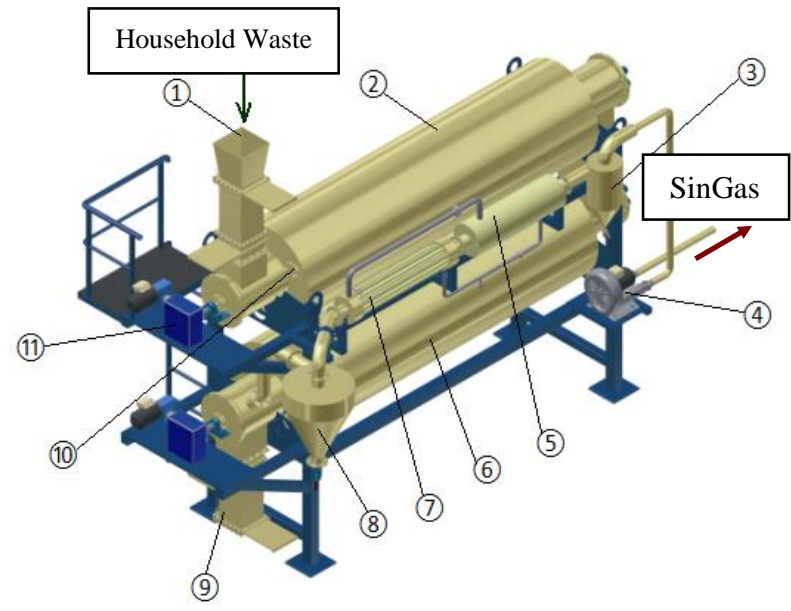

Fig. 3: SinGas Generator

1. feeder, 2. primary reactor, 3. fine particle cyclone, 4. circular pump, 5. accumulator, 6 . secondary reactor, 7. primary cooler, 8 . primary cyclone filter, 9 . ash residue drain, 10. electrical resistance, 11.gearbox shneck

The basic advantage of the technology consists in the possibility of converting the mass of garbage and biomass into the single, by complete oxidation, for the subsequent production of electricity by using the synthesis gas in the form of fuel for an internal combustion engine, to which a generator is coupled. electric.

This way you can get electricity.

The pollution is given by the thermal engine, as a result of the reactor process results in an amount of ash, which can be used in construction (concrete) or wear material for the asphalt carpet.

Biomass pyrolysis is a thermochemical process of converting an organic matter into a gaseous product (sinGas) through its partial oxidation. The process takes place at very high temperatures, with small amounts of air, in order not to allow the complete burning of the biomass, but which is sufficient for gasification. The temperature indicated is achieved by means of high power electrical resistors located inside the reactor, so at a temperature of at least $700{ }^{\circ} \mathrm{C}$ the synthesis gas results.

Through the process of pyrolysis of matter, solid biomass is transformed into a mixture of gases. Its basic components are hydrogen $(\mathrm{H} 2)$, methane $(\mathrm{CH} 4)$ and carbon monoxide $(\mathrm{CO})$, see reactions below.

In addition, carbon monoxide (CO2), nitrogen (N2) and other inert gases are included in the composition.

The main element of a solid biomass pyrolysis plant is the gasified, also called the reactor. The installation also includes a primary / secondary gas filtration and purification system, a tubular cooling system and a storage facility for the single gas obtained.

The conversion of the biomass begins with the drying and breaking processes, after which it is directed to the pyrolysis reactor hopper, by means of a sneck which ensures the mass movement inside the reactor, (Fig.3).

\section{Rural community}

Development of a pilot system of integrated waste management at the rural community must first identify for potential suppliers of raw materials (organic waste, household waste).

The commune of Ogra belonging to the county of Mures. It is a commune consisting of 5 villages: Dileul Vechi, Giuluş, Lăscud, Ogra (residence) and Vaideu. according to the 2011 census the commune's population rises to 2,387 inhabitants, the community presents 3 agricultural associations totaling 3 cows farms, 25 satiety food stores and a used tire depot, [11], [12].

The amount of waste collected weekly from the population is 32 tones / week. From the 3 farms can collect household waste that can be the material basis for fermentation and obtaining biogas. 


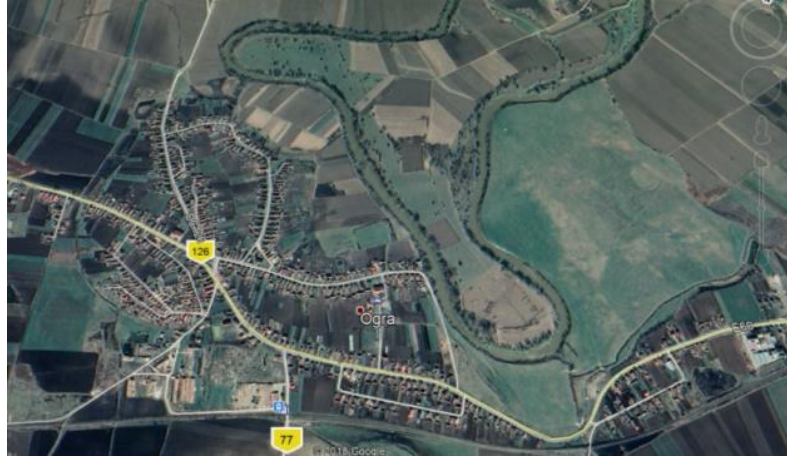

Fig. 4: Ogra Commune - Mures County [13]

The development of an integrated waste management system in the rural area, implies the organization and establishment of a rigorous plan for selective collection of household waste. It is proposed to selectively collect household waste from each household twice a week, and the manure will be collected once a month. The organization will be highlighted in the villages.

The selective collection is done with equipped in collaboration with the economic agents and the management of the garbage dump at Sîmpaul.

In Fig. 5 is shown schematically the organization of a management system of the activity served at the rural community level.

\section{Motivation of the population}

Informing the population will be done through different promotional campaigns through regular meetings with the locals. Establishing a rigorous program for selective collection and collection of household garbage, ensuring paid jobs from the budget of the Ogra commune administration.

For each village town hall, a department will be organized that will be responsible for the sanitation and ecology of the village area and will be subordinated to the waste management department of the Ogra commune, [1], [6].

Selective waste collection will be done weekly from the collection point platforms.

In order to improve the process of selective recycling and collection, an audit is proposed at the level of the common structure, village, organization, to identify new solutions implemented in the SIMD system.

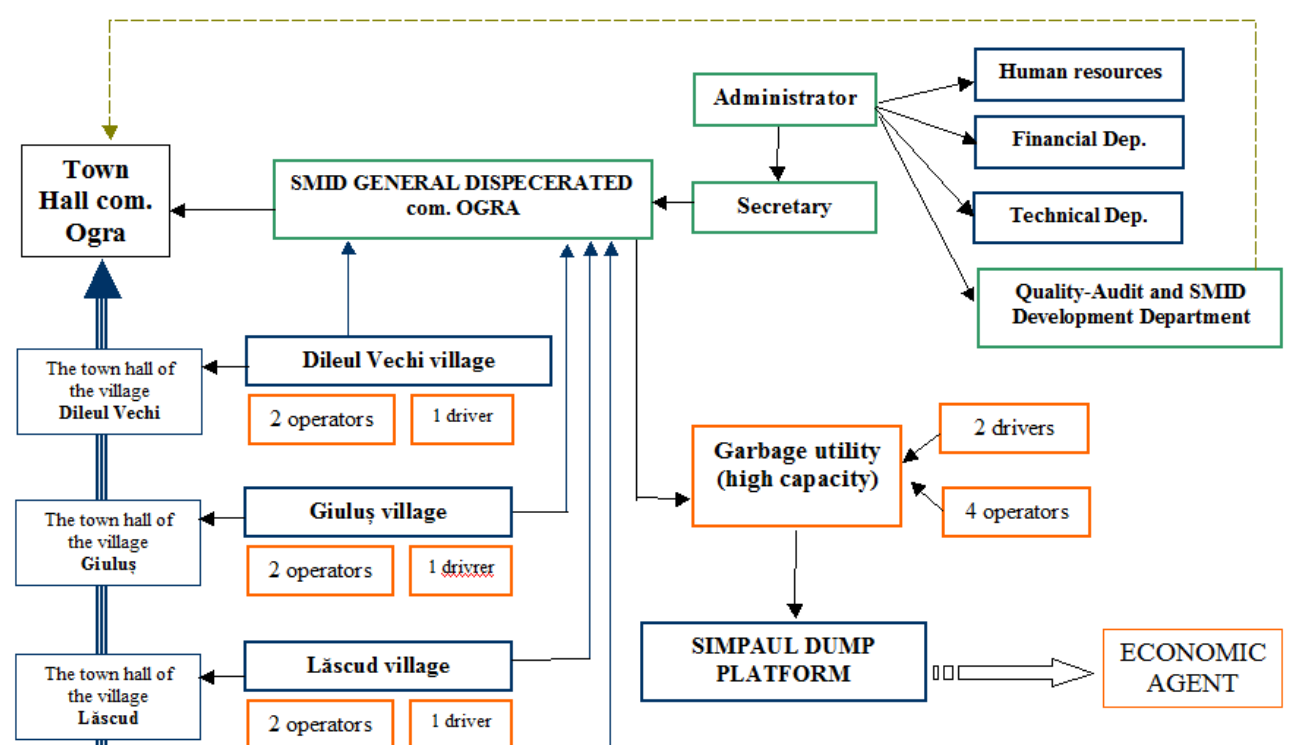

Fig. 5: SIDM organizational chart proposal

with the Europeans for selective recycling vehicles. for each village belonging to the commune of Ogra, the location of a specific platform for selective collection and biomass from household will be established, [14], [15].

The management of the collection activity at the village level is ensured and coordinated by the local town halls in the village, and the management, organization and management of the waste will be ensured by the administration of the Ogra commune

\section{Results and discussion}

Following the block diagram you can seen in Fig.6, the proposal for an integrated waste management system organized at rural community level is highlighted, representing a pilot model that can be analyzed, improved and implemented according to the unforeseen situations.

The development and implementation of a SMID system is more difficult to motivate in the rural area, because everything that means household or organic waste burns on the field by the inhabitants, 
considering that the resultant ash is a organic fertilizer, in this sense the campaigns of promotion, awareness are welcome. and for clearing the inhabitants of the rural area for the implementation of an integrated system of waste management.

\section{Conclusions}

In order to develop intelligent waste recovery, the following objectives are achieved:

-Improving the quality of the environment and protecting the health of the population;

-Encouraging green investments;

-Increasing the efficiency of the use of resources;

-Develop responsible behaviour regarding the prevention of waste generation and management.

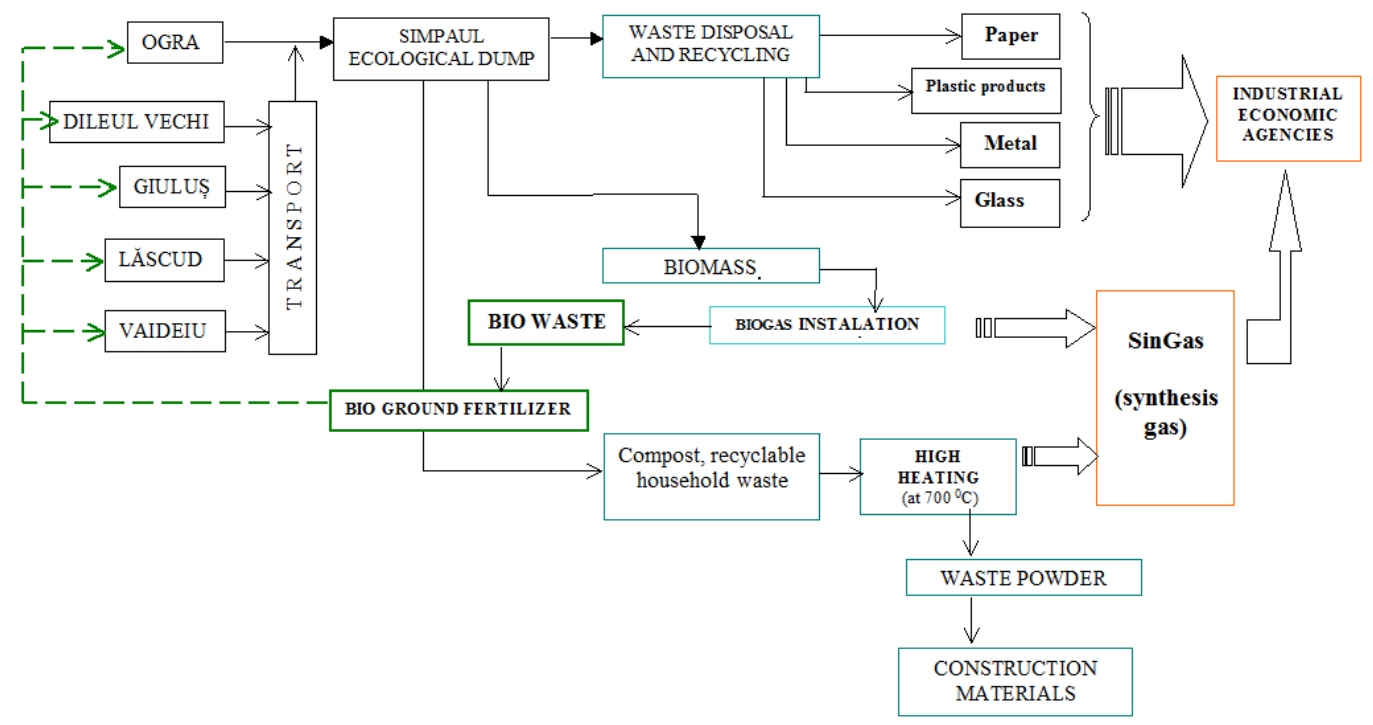

Fig. 6: Proposed block diagram of a SMID implemented in the rural area of the Ogra commune

\section{References}

[1] AEA Technology and AEA Mediu Consulting, (2008), Study on the revision of the National Waste Management Strategy.

[2] Bovea, M. D., Ibáñez-Forés V., Gallardo A., Colomer-Mendoza F.J. (2010), Environmental assessment of alternative municipal solid waste management strategies. A Spanish case study, Waste Management.

[3] Bucur A. (2019), Aspects of the population awareness strategy for improving the quality of the environment. Case study in the rural area. Elsevier Procedia Manufacturing 13th International Conference Interdisciplinarity in Engineering (INTER-ENG 2019 - being edited).

[4] Cherubini, F., Bargigli, S., Ulgiati, S. (2008), Life cycle assessment of urban waste management: Energy performances and environmental impacts. The case of Rome, Italy, Waste Management 28 (2008) 2552-2564;

[5] Cleary, J. (2009), Life cycle assessments of municipal solid waste management systems: A comparative analysis of selected peer-reviewed literature, Environment International 35.
[6] Mureş County Council, Mureş County Development Program 2007-2013, Published: http://www.cjmures.ro;

[7] Manfredi S., Christensen, T.H. (2009), Environmental assessment of solid waste landfilling technologies by means of LCAmodeling, Waste Management 29, 32-43.

[8] Modoi O. C., Ozunu Al. (2012), Practical applications in the field of solid waste management, Cluj Napoca, EFES Publishing House.

[9] Subhash A.Solid (2010), Waste Management, Mittal Publishing House.

[10] Sunil K. (2011), Integrated Waste Management, vol. 1, InTech Publishing House.

[11] http://www.recensamantromania.ro/rezultate-2/

[12] https://primariaogra.ro/

[13] https://www.google.ro/maps

[14]http://www.traiverde.ro/ Guide to waste management

[15]http://www.gestiunedeseuri.ro/prezentare-

proiect.html, Project: Partnership for a clean environment, waste reduction and sustainable development in the $7^{\text {th }}$ Center Region. [16]https://www.journals.elsevier.com/wastemanagement 